\title{
A Fundação Rockefeller e a campanha de erradicação da ancilostomíase em São Paulo (1917-1926)
}

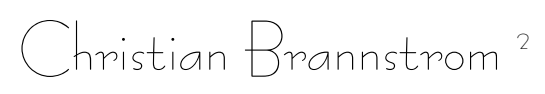

"A entrada de um trabalhador apto para a nossa lavoura representa uma pequena fortuna. Esse trabalhador valerá o seu peso em ouro. Trazel-o, pois, na quantidade e na qualidade requeridas, é inocular a vida na nossa vida, é elevar S. Paulo a uma posicao de grandeza nacional e material tal que o fará resplendecer como astro de primeira grandeza, já não só no Brasil, mas á face de todo o universo". ${ }^{3}$

"Um individuo, roido pelos vermes, é como o fruto bichado-imprestavel ou aproveitavel sómente em parte. É um paiz de população inferiorisada pela bicharia [e] é como a madeira minada pelo cumpim. Só tem casca; o miolo é farello. A parte da população brasileira mais estragada pela verminose especialmente pela mais grave-a ancylostomose [--] é a rural, a que tira da terra os elementos da vida da nação, a que faze a agricultura e a pecuaria, legitimas fontes de riqueza de um paiz vasto e pouco povoado, a base da economia nacional, e a fonte biologica da nacionalidade. É ella ainda quem alimenta o

\footnotetext{
${ }^{1}$ Texto revisto e ampliado do original "Polluted Soil, polluted souls; the Rockefeller hookworm erradication campaign in São Paulo, Brazil, 1917-1926”. Historical Geography, Volume 25, 1997: 25-45. Tradução de Cláudio DeNipoti.

${ }^{2}$ Associate Professor, Departamento de Geografia Texas A\&M University, Estados Unidos.

${ }^{3}$ LEAL, Justo. O braço para a lavoura. Revista dos fazendeiros 3(1920), s./p. A mesma revisa contém outros artigos lamentando a falta de trabalhadores rurais nas lavouras cafeeiras, publicados com título "a falta de braços": Revista dos Fazendeiros 2, no. 16 (1919): s/p; Revista dos Fazendeiros 2, no. 16 (1919): $\mathrm{s} / \mathrm{p}$; LUZ, Christiani. O problema da falta de braços. Revista dos fazendeiros 3 (1920). s.p.
} 
A Fundação Rockefeller e a campanha de eradicação da ancilostomíase...

luxo das cidades, e esse polvo monstro, hypocriticamente chamada industria nacional..."4

"Os outros, que falam francez, dançam o tango, pitam havanas e, senhores de tudo, te manteem nessa gehenna dolorosa, para que possam a seu salvo viver vida folgada á custa do teu pennoso trabalho, esses, caro Jéca, têm na alma todas as verminosas que tu só tens no corpo". ${ }^{5}$

As atividades da Diretoria Internacional de Saúde (International Health Board - IHB) da Fundação Rockefeller (FR) no início do século XX, em São Paulo, estiveram relacionadas a campanhas filantrópicas de saúde pública, relativamente sem distinção. Durante um período de dez anos de erradicação da ancilostomíase e do estabelecimento de centros municipais de saúde pública, houve pouca resistência e foram poucos os conflitos abertos entre a IHB e funcionários e oficiais brasileiros. Mas, vale destacar, a região da atividade da IHB em São Paulo era o território das principais elites exportadoras e industriais de café da América Latina (Figura 1, Tabela 1). Também, o momento em que a IHB desenvolveu as suas atividades foi significativo: numa época de intensas discussões sobre trabalhadores rurais e imigração - Justo Leal, na Revista dos Fazendeiros, argumentava pela importação de trabalhadores, enquanto Belisário Pena

\footnotetext{
${ }^{4}$ PENNA, Belisario. Saneamento do Brasil. Rio de Janeiro: Jacintho Ribeiro dos Santos, 1923, 2a. ed. p. 211-212. Sobre Penna, ver: REZENDE, Joffre M. de. A Viagem Científica de Neiva e Penna: Roteiro Para os Estudos das Doenças do Sertão. História, Ciências, Saúde--Manguinhos 16 (2009): 265-88; BLAKE, Stanley S. The Medicalization of Nordestinos: Public Health and Regional Identity in Northeastern Brazil, 1889-1930. The Americas 60, no. 2 (2003): 217-48; SANTOS, Luiz Antonio de Castro e Lina Rodrigues de FARIA, A Reforma Sanitária no Brasil: Ecos da Primeira República. Bragança Paulista: EDUSF, 2003, p. 45-7.

${ }^{5}$ LOBATO, José Bento Monteiro. Urupês. São Paulo: Editora Monteiro Lobato, 1923, 9a ed. Essa passagem vem da "Explicação desnecessária" de Monteiro Lobato, reimpressa da quarta edição de Urupês, publicada em 1919. Jeca-Tatu representava os pequenos proprietários e trabalhadores rurais brasileiros pobres e doentes. "Ressuscitado" pelos esforços contra o amarelão, Jeca Tatu se tornou um fazendeiro capitalista bem sucedido. Ver: BORGES, Dain. Puffy, ugly, slothful and inert; degeneration in Brazilian social thought, 1880-1940. Journal of Latin American Studies 25 (1993): 235-56.
} 
sustentava a tese da reabilitação de trabalhadores rurais como projeto nacional - a IHB surgiu com uma iniciativa de saúde pública que tinha o potencial de reduzir a incidência da ancilostomiase e melhorar a infraestrutura de saúde rural do Estado. A campanha da IHB também ajudou a criar a base científica para consolidar a interligação entre os discursos sanitarista e eugênico.

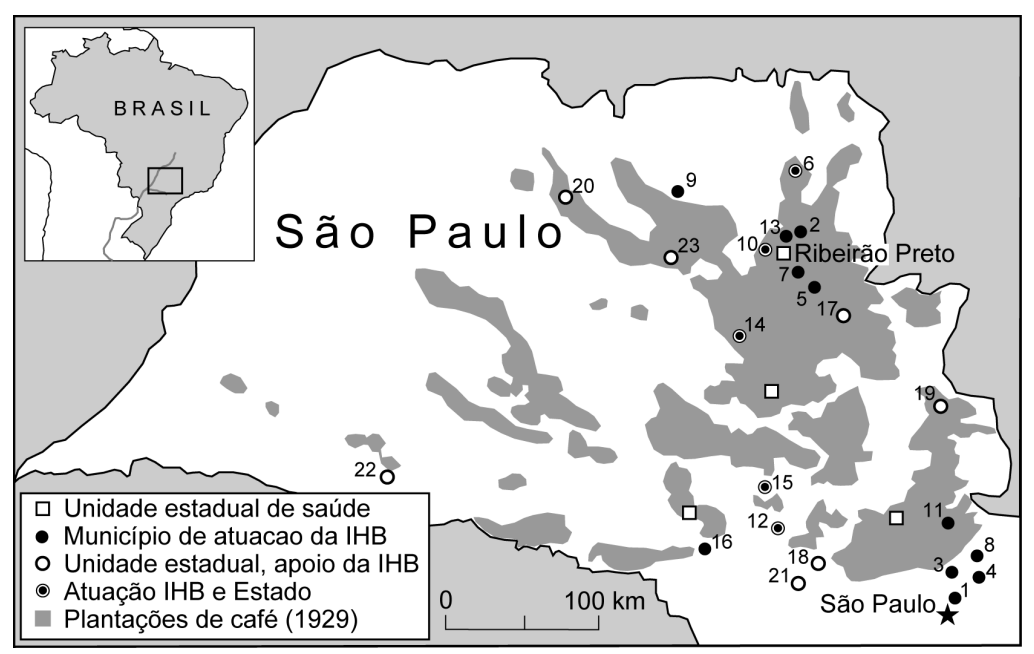

FIGURA 1: Atividades da Fundação Rockefeller em São Paulo, 1917 a 1926. Os lugares identificados referem-se ao centro urbano do município. Ver Tabela 1 para os dados sobre a produção do café 1918/19. Fontes: Tabelas 3 e 4; Pierre MONBEIG, Pionniers et planteurs de São Paulo (Paris, Armand Colin), p. 167.

A partir da discussão sobre a filantropia da IHB em São Paulo, o objetivo deste ensaio é obter uma nova perspectiva das ações das elites do café daquele estado. De particular interesse é a caracterização das elites próimigração e anti-saúde pública, uma afirmação simplista demais para explicar a interação entre os agentes da IHB e os cafeicultores paulistas. Estabelecerei, primeiro, o contexto 
da filantropia do IHB em São Paulo, enfocando na questão da imigração e nos discursos sanitaristas e eugênicos. Em seguida, analisarei os detalhes da atividade de saúde pública da IHB, incluindo as suas observações feitas em experiências de campo. A conclusão levanta questões sobre a interação entre a IHB e as elites, sobre a seleção de municípios para a atividade da IHB e sobre a falta da construção de latrinas na campanha da IHB. ${ }^{6}$

\section{Café, trabalho e saúde em São Paulo no início do século $\mathrm{XX}$}

Segundo Steven Palmer, a ancilostomíase foi um problema global durante os séculos XIX e XX, que, junto com outras doenças, teria acompanhado o desenvolvimento da fronteira agrícola, com plantações à grande escala, atraindo trabalhadores rurais cujos "corpos vulneráveis foram aglomerados para trabalho duro [amassed for hard labor]." Um bom exemplo desse fenômeno é o caso da produção do café no Estado de São Paulo, onde vemos que a introdução constante de imigrantes europeus poderia distanciar as elites da necessidade de uma postura favorável à saúde pública, como sugeriu Justo Leal na epígrafe. Porém, quando a

\footnotetext{
${ }^{6}$ As fontes utilizadas estão no Rockfeller Archive Center, North Tarrytown, NY (daqui em diante referenciada como RAC), Rockfeller Foundation Archives (daqui em diante, RFA). Os arquivos de correspondência (Séries 1 e 1.2) são basicamente relacionados à questões de rotina, mas há algumas cartas reveladoras sobre o estabelecimento de programas e interação com instituições ou indivíduos estrangeiros. Relatórios bimestrais e anuais dos escritórios de campo (Séries 2 e 3) fornecem detalhes sobre as atividades diárias das campanhas de saúde pública. Documentos de ambas as séries, bem como fotografias, foram usadas na preparação dos relatórios anuais publicados. Vários funcionários importantes da Fundação Rockfeller mantinham diários, como era exigido deles. Guías exelente encontra-se em dois trabalhos: FARIA, Lina Rodrigues de, Arquivo Rockefeller. História, Ciências, Saúde--Manguinhos 1, no. 2 (1994/1995): 117-28; e CASTROSANTOS, Luiz A. de, e Lina Rodrigues de Faria, Arquivo Rockefeller: Banco de Dados, 1920-1965 (Rio de Janeiro: Universidade do Estado do Rio de Janeiro, Instituto de Medicina Social, 1996).

${ }^{7}$ Steven PALMER, "Migrant Clinics and Hookworm Science: Peripheral Origins of International Health." Bulletin of the History of Medicine 83, no. 4 (2009): 679.
} 
fonte de imigração foi interrompida pela Primeira Guerra Mundial, uma maior preocupação com a saúde pública foi possivel. A questão do trabalhador para o café coincidiu com o alinhamento do pensamento eugênico com o movimento sanitarista, que, por sua vez, estabeleceu o contexto para a entrada da FR no Estado de São Paulo.

Entre as elites cafeicultoras de São Paulo, o trabalho era um tópico de intensa discussão: quem faria o trabalho necessário para a produção de café? Os trabalhadores rurais, dos quais as elites dependiam para plantar, carpir, colher e secar o café nas fazendas, deveriam ser nativos ou imigrantes? Se fossem imigrantes, como esperavam as elites do café, o Estado deveria aumentar fundos públicos para superar o declínio da imigração europeia a partir do final da Primeira Guerra Mundial.

Tabela 1 : número de pés de café e produção nos municípios de atuação da IHB, 1918-1919

\begin{tabular}{c|c|c}
\hline Município & Num. de pés de café (milhões) & $\begin{array}{c}\text { Produção de Café (mil } \\
\text { toneladas) }\end{array}$ \\
\hline 1. Guarulhos & n.d. & n.d. \\
\hline 2. Brodósqui & 3,8 & 2,49 \\
\hline 3. Atibaia & 7,2 & 2,25 \\
\hline 4. Nazaré & 0,64 & 0,18 \\
\hline 5. São Simão & 22,0 & 10,2 \\
\hline 6. Orlândia & 10,25 & 7,89 \\
\hline 7. Cravinhos & 11,29 & 9,84 \\
\hline 8. Piracaia & 3,79 & 1,62 \\
\hline 9. Viradouro & 2,32 & 1,13 \\
\hline 10. Sertãozinho & 15,62 & 12,6 \\
\hline 11. Bragança & 10,57 & 5,25 \\
\hline 12. Tietê & 6,27 & 2,94 \\
\hline 13. Jardinópolis & 7,46 & 6,27 \\
\hline 14. Araraquara & 18,21 & 9,11 \\
\hline 15. Piracicaba & 6,25 & 2,4 \\
\hline 16. Angatuba & 0,95 & 0,33 \\
\hline 17. Santa Rita do Passaquatro & 11,04 & 5,1 \\
\hline 18. Itu & 5,99 & 3,03 \\
\hline & &
\end{tabular}

continua 
A Fundação Rockefeller e a campanha de eradicação da ancilostomíase...

continuação

\begin{tabular}{c|c|c}
\hline 19. Espírito Santo do Pinhal & 11,0 & 7,35 \\
\hline 20. São José do Rio Preto & 3,18 & 2,04 \\
\hline 21. Sorocaba & n.d. & n.d. \\
\hline 22. Cândido Mota & n.d. & n.d. \\
\hline 23. Taquaritinga & 14,62 & 8,78 \\
\hline São Paulo - total & $\mathbf{8 2 8 , 3 6}$ & $\mathbf{4 3 5 , 2}$ \\
\hline
\end{tabular}

Fonte: Estado de São Paulo. Secretaria de Agricultura, Comércio e Obras Públicas. O café: Estatística de produção e commercio, 1919. São Paulo: Escolas Profissionais do Lyceu Salesiano Sagrado C. de Jesus, 1920, p. 18-22.

A imigração em massa, subsidiada pelo Estado, já havia criado o mercado de trabalho rural tão crucial para o sucesso da agroexportação das elites cafeeiras paulistas (Tabela 2). Entre 1882 e 1934, mais de 2,3 milhões de imigrantes chegaram em São Paulo. Durante a maior parte deste periodo, os cafeicultores canalizaram os fundos públicos para os custos logísticos e de transporte dos agricultores europeus para os cafezais paulistas. Para as elites cafeeiras, a queda na imigração entre 1915-1920 causou uma crise no mercado de trabalho rural e fez com que alguns cafeicultores defendessem políticas pró-imigração renovadas. Enquanto a literatura existente afirma que as elites cafeeiras se opunham a políticas de saúde pública direcionadas à melhoria da saúde dos trabalhadores rurais, as evidências apresentadas abaixo sugerem que algumas elites apoiavam a IHB e sua presença na saúde pública, e até justificavam o seu apoio baseando-se nos discursos de Monteiro Lobato e Belisário Pena. No contexto das atividades da IHB em São Paulo, é possivel que as elites se opusessem à legislação de saúde pública, mas, em suas propriedades cafeeiras, apoiavam o trabalho dos funcionários da Fundação Rockfeller. Por exemplo, segundo Lina Faria, o Partido Republicano Paulista facilitou a negociação entre o governo e os fazendeiros, pois "as oligarquias não viam com bons olhos a intervenção direta do governo estadual em suas fazendas". Essa negociação foi parte da "modernização conservadora" que ela descreve: "a saúde pública foi um instrumental para a modernização 
da estrutura econômica e administrativa do Estado de São Paulo"s

Milhares de imigrantes europeus e de brasileiros trabalharam sob o sistema de trabalho de colonato, um sistema misto de trabalho por tarefa e porcentagem que existiu nos cafezais de São Paulo entre as décadas de 1880 e 1960. Com a substituição da escravidão nas propriedades cafeeiras paulistas, a remuneração pelo colonato incluía uma taxa fixa anual para a limpeza de mil pés de café, e uma taxa por unidade, para a colheita. Para atrair familias de colonos, os fazendeiros davam direitos de usufruto para a plantação de produtos de subsistência ou de mercado entre as fileiras de pés de café, ou em outra parte da propriedade. Algumas das muitas variações dos tipos individuais de fazendas de café incluíam tempo de contrato, qualidade dos alojamentos, preços de insumos que os colonos compravam, acesso aos mercados para a produção de alimentos dos colonos, e as normas de plantio de alimentos nos intervalos das fileiras de pés de café ou em local separado. Esse sistema flexivel permitia que os cafeicultores reduzissem os custos da mãode-obra durante periodos de preços baixos do café, oferecia um incentivo para que as famílias cuidassem de grandes números de pés de café e transferia a coerção sobre o trabalho familiar para o chefe do domicílio. Os colonos frequentemente tentavam antecipar o fim dos seus contratos para se mudarem para propriedades na região que tivessem melhores termos de contrato, ou para imigrar para o oeste do Estado, para novas terras produtoras de café. ${ }^{9}$

${ }^{8}$ FARIA, Fundação Rockefeller, 564; SANTOS e FARIA, Reforma Sanitária, 141; RIBEIRO, Maria Alice Rosa. História sem fim... inventário da saúde pública- São Paulo, 1880-1930. São Paulo: Editora da Unesp, 1993, p. 176-80; HOLLOWAY, Thomas H. Imigrantes para o café. Café e sociedade em São Paulo, 1886-1934. Trad Eglê Malheiros. Rio de Janeiro: Paz e Terra, 1984, p. 61-109. Para elites cafeeiras opostas a melhorias de saúde pública, ver RIBEIRO, Saúde pública, 213 e BLOUNT, John Allen. The public health movement in São Paulo, Brazil; a history of the Sanitary Service, 1892-1918. Tese. Doutorado. Tulane University, 1971 , p. 143-55.

${ }^{9}$ ALVIM, Zuleika M. F. Brava gente! Os italianos em São Paulo. (1870-1920). São Paulo: Brasiliense, 1986, p. 74-114; DEAN, Warren. Rio Claro; a Brazilian plantation system. Stanford: Stanford University Press, 1976, p. 161-91; 
A Fundação Rockefeller e a campanha de eradicação da ancilostomíase...

Tabela 2: Imigração para São Paulo. Partidas da terceira classe do Porto de Santos, São Paulo e partidas de imigrantes para a região de Ribeirão Preto

\begin{tabular}{c|c|c|c}
\hline Ano & Imigração & Partidas de Santos & De São Paulo a Ribeirão Preto \\
\hline 1910 & 39486 & 30761 & 9793 \\
\hline 1911 & 61508 & 37331 & 10735 \\
\hline 1912 & 98640 & 37440 & 16104 \\
\hline 1913 & 116640 & 41145 & 24379 \\
\hline 1914 & 46624 & 41834 & 15997 \\
\hline 1915 & 15614 & 26183 & 5574 \\
\hline 1916 & 17011 & 12776 & 5387 \\
\hline 1917 & 23407 & 9397 & 7616 \\
\hline 1918 & 11447 & 6542 & 4756 \\
\hline 1919 & 16205 & 14509 & 4113 \\
\hline 1920 & 31854 & 16748 & 6881 \\
\hline 1921 & 32978 & 16796 & 7723 \\
\hline 1922 & 31281 & 20612 & 5165 \\
\hline 1923 & 45240 & 20697 & 5882 \\
\hline 1924 & 56085 & 24085 & 9920 \\
\hline 1925 & 57429 & 26304 & 10537 \\
\hline 1926 & 76796 & 26425 & 7518 \\
\hline 1927 & 61607 & 26591 & 13857 \\
\hline TOTAL & $\mathbf{8 3 9 5 5 2}$ & $\mathbf{4 3 6 1 7 6}$ & $\mathbf{1 7 1 9 3 7}$ \\
\hline
\end{tabular}

Fonte: HOLLOWAY, Thomas H. Imigrantes para o café. Café e sociedade em São Paulo, 1886-1934. Trad Eglê Malheiros. Rio de Janeiro: Paz e Terra, 1984, p.265-6.

Mas, se os cafezais dependessem de trabalhadores brasileiros, o problema seria como fazê-los trabalhar mais. Em vez de imigração subsidiada, o estado teria que montar novos esforços para melhorar a saúde dos trabalhadores rurais. Nesse periodo, no final da década de 1910, acontece o trabalho da IHB no Brasil que ajudou a criar uma base

$\overline{\text { HOLlOWAY, Imigrantes para o café; MONBEIG, Pierre. Pioneiros e fazendeiros de }}$ São Paulo. Trad. Ary França e Raul de Andrade e Silva. São Paulo: Hucitec/ Polis, 1984, p. 147-62; STOLCKE, Verena. Cafeicultura: homens, mulheres e capital. São Paulo: Brasiliense, 1986; BRANNSTROM, Christian, Coffee Labor Regimes and Deforestation on a Brazilian Frontier, 1915-1965. Economic Geography 76, no. 4 (2000): 326-46. 
material que sustentou e apoiou os vínculos entre os protagonistas do movimento em prol do saneamento e os proponentes da eugenia no Brasil. Vale destacar que a eugenia brasileira era bem distinta da eugenia dos EUA ou Alemanha. A versão brasileira da eugenia era a positiva ou preventiva, e possuía uma forte ligação com o saneamento e a saúde pública. Segundo um estudo recente, "o pensamento eugênico brasileiro se ligou intimamente ao movimento sanitarista iniciado no começo do século XX". ${ }^{10}$ Uma articulação dessas idéias alcançou audiências populares no trabalho de José Bento Monteiro Lobato que, entre 1914 e 1919, criou duas versões da conhecida figura alegórica do Jeca Tatu, em uma série de ensaios. Inicialmente, em 1914, Monteiro Lobato descreveu Jeca Tatu como um "funesto parasita da terra" que era "semi-nomade, inadaptavel á civilização, mas que vive á beira dela na penumbra das zonas fronteiriças." 11 Esta intervenção levantou grande polêmica na época. Um autor criticou a invenção da figura de Jeca Tatu e ofereceu uma contra-figura, o Mané Chique-Chique. Como notou Thomas Skidmore, Monteiro Lobato logo depois converteu-se no porta-voz da campanha para "educar a elite sobre os problemas econômicos e sociais do Brasil" e juntou forças com sanitaristas que argumentavam que a doença, não a raça, seria a causa principal do atraso do meio rural. Monteiro Lobato agora culpava mesmo as "elites" pelas doenças dos brasileiros do campo e sugeria que trabalhadores "curados" tornar-se-iam pequenos proprietários - e não somente proletários rurais saudáveis: "Eu ignorava que eras assim, meu caro Tatú, por motivo de doenças tremendas. Está provado que tens no sangue e nas tripas um jardim

\footnotetext{
${ }^{10}$ KOBAYASHI, Elisabete, Lina FARIA e Maria Conceição da COSTA, "Eugenia e Fundação Rockefeller no Brasil: A Saúde como Proposta de Regeneração Nacional." Sociologias 11, no. 22 (2009): 328; STEPAN, Nancy Leys, "The hour of eugenics:" Race, gender, and nation in Latin America (Ithaca: Cornell University Press, 1991), p. 157.

${ }^{11}$ LOBATO, "Velha praga," Urupês. Obras completas de Monteiro Lobato (São Paulo: Brasiliense, 1961), 271.
} 
zoologico da peior especie. É essa bicharia cruel que te faz papudo, feio, mollenga, inerte."12

Aqueles que acreditavam em uma tal presença do Estado na saúde, como o alto funcionário sanitário do Rio de Janeiro, e respeitado vice-presidente honorário da Sociedade Eugênica de São Paulo, Belisário Penna, argumentavam que era exequivel curar trabalhadores debilitados pela ancilostomíase, tracoma e malária, nas regiões cafeeiras de São Paulo, defendendo que o tratamento de doenças poderia render mais ao fazendeiro. A transformação de Jeca Tatu consolidou, no discurso, a interligação entre o pensamento eugênico e o movimento sanitarista. Belisário Pena, na segunda edição de Saneamento do Brasil, publicada em 1923, incluiu muitas referências ao Jeca Tatú curado da ancilostomíase. Uma imagem do seu livro mostrou o "contraste" entre trabalhadores rurais com "bom sangue" e "mau sangue" (Figura 2: "contraste"). Pena colocou "um Jeca authentico, antes e depois de curado de opilação", e também colocou o contraste entre a moradia do "Jeca" antes e depois do saneamento (Figura 3: "authentico Jeca"). O mesmo discurso foi adotado pelo líder do movimento eugenista brasileiro, Renato Kehl: "expurguem-se-lhes dos parasitas, dêem se-lhes calçados, prohibam-lhes de acocorar de gorilhas, alimentem-se-lhes um pouco melhor que os animaes de estimação e veremos o Geca Tatú, o Geca Mollengo se enfibrar, se enrijar, se hominisar, tomando-se um Geca Bravo, um Geca Valente, um Geca duro como guarantã, activo, trabalhador, corado, musculoso - forte, em summa". Essas imagens duraram décadas, formando parte da cultura popular brasileira. Por exemplo, no início da década de 1950, a farmacêutica Fontoura publicou um reclame numa revista dirigida às elites cafeiras, usando o mesmo discurso: "Agora ele é outro homem", curado dos "vermes que infestam seus intestinos" (Figura 4). ${ }^{13}$

${ }^{12}$ LOBATO, "Explicação desnecessária", x; SKIDMORE, Thomas E., Black into white: Race and nationality in Brazilian thought. New York: Oxford University Press, 1974, p. 168 e 180-84.

${ }^{13}$ PENNA, Saneamento; "Agora ele é outro homem," Boletim da Superintendência dos Serviços do Café, vol. 26, no. 294 (agosto de 1951), p. 654; KEHL, Renato. Eu- 


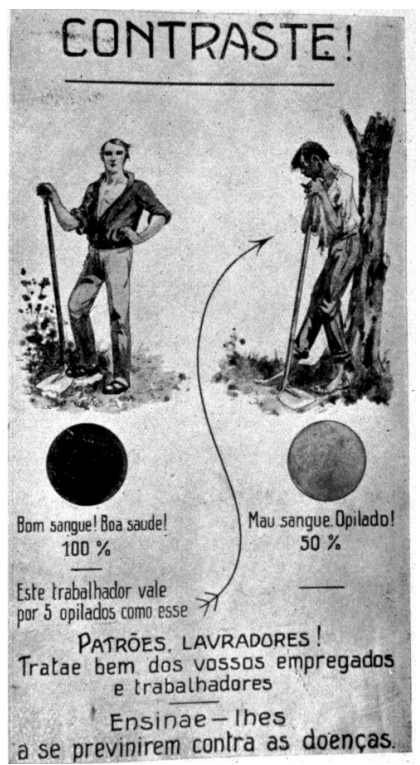

Figura 2: Argumento de Belisário Pena, mostrando como um trabalhador sem doenças poderia valer "por 5 opilados." PENNA, Saneamento, 233.

genia e Medicina Social (Problemas da Vida). 2a ed. Rio de Janeiro: Livraria Francisco Alves, 1923, p. 203. Provavelmete, Monteiro Lobato soube de Kehl apenas em 1918, quando Monteiro Lobato dirigiu uma carta ao Kehl apos ler o texto de uma conferência de Kehl. Ver: SOUZA, Vanderlei Sebastião de. "Em Nome da Raça: Propaganda Eugênica e as Idéias de Renato Kehl nos Anos 1910 e 1920." Revista de História Regional 11, no. 2 (2006): 32-3. Em 1924, Monteiro Lobato e Cândido Fontoura lançaram o folheto "Jeca Tatuzinho" para promover vendas de Biotônico Fontoura e Ankilostomina Fontoura. Mais de 100 milhões de exemplares foram imprimidos. O folheto é considerado um dos mais bem-sucedidos exemplos da propaganda brasileira; ver http://lobato.globo.com/misc_jeca.asp. 
A Fundação Rockefeller e a campanha de eradicação da ancilostomíase...

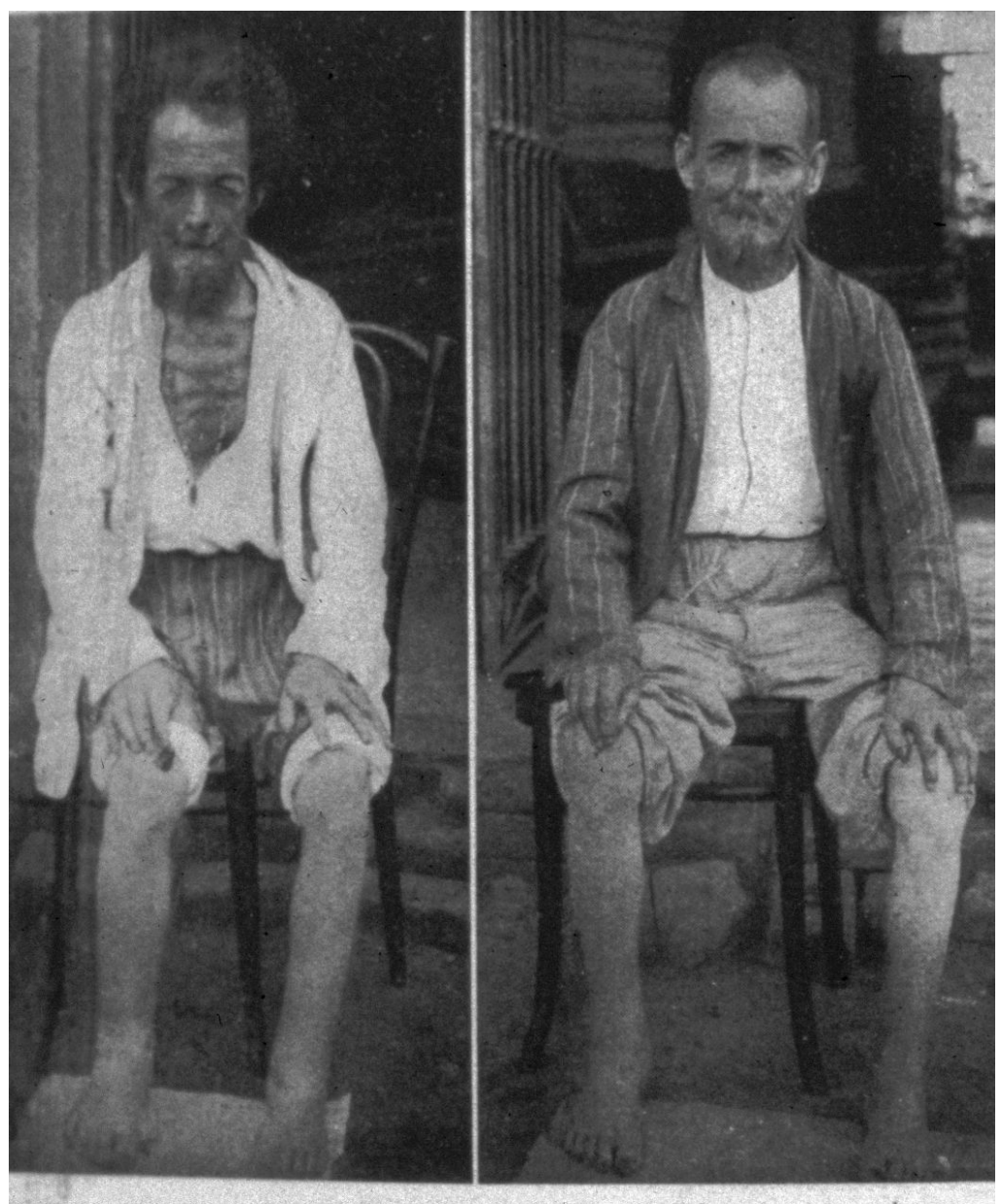

Um Jeca authentico, antes e depois de curado da opilacão

Figura 3: Exemplo de um "Jeca authentico" indicando os efeitos positivos de melhoramento da saúde pública. PENNA, Saneamento, 212. 


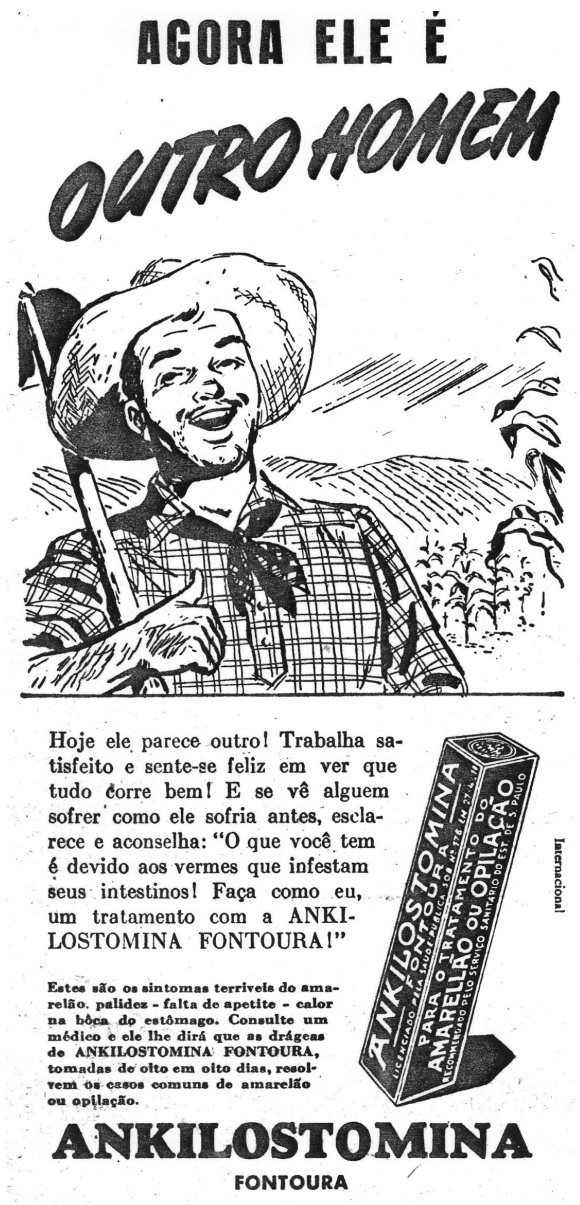

DESTRÓI E ELIMINA OS VERMES dO AMARELÃOI

Figura 4: Propaganda dirigido aos produtores de café do início da década de 1950, de Fontoura por seu produto contra ancilostomíase. O discurso de criar "outro homem" é evidente no período do trabalho da Fundação Rockefeller. Boletim da Superintendência dos Serviços do Café vol. 26, no. 294, agosto de 1951, p. 654. 
Esta fusão de ideias da eugenia e do movimento sanitarista aconteceu justamente no momento em que a IHB desenvolvia os seus estudos em São Paulo. Sabemos que, no livro de Belisário Pena, este agradeceu a Lewis Hackett, o diretor da IHB no Brasil, por dados fornecidos referentes à ancilostomíase. ${ }^{14}$ Porém, nem o vínculo, nem o próprio trabalho da IHB, está claramente descrito na bibliografia. Por exemplo, Dain Borges indica que Monteiro Lobato foi "influenciado pelos levantamentos de saúde rural", porém não indica que foi a IHB que comandou o levantamento em São Paulo. Também Skidmore não indica por que Monteiro Lobato começou a argumentar que Jeca Tatu poderia ser transformado num agricultor bem-sucedido. Outro argumento, mais recente, é que a Fundação Rockefeller teve "envolvimento" no movimento eugenista no Brasil. Mas esse argumento ainda necessita especificar os mecanismos e os meios desse envolvimento. ${ }^{15}$ Falta ainda um entendimento melhor do que a RF fez, no meio rural paulista, que poderia ter fornecido subsídios aos vínculos entre o pensamento eugênico e o movimento sanitarista.

\section{A Diretoria Internacional de Saúde (IHB) da Fundação Rockefeller}

A Fundação Rockefeller criou a IHB (inicialmente chamada de Comissão Internacional de Saúde e, mais tarde, Divisão Internacional de Saúde), em 1913, para ampliar os esforços contra a ancilostomíase no sul dos Estados Unidos e outros países. Funcionários da FR estimaram que 900 milhões, da população mundial de 1,6 bilhões de pessoas, viviam em uma "zona infectada". No Brasil, a IHB estimou que 15 milhões de pessoas estavam infectadas, e que a inci-

\footnotetext{
${ }^{14}$ PENNA, Saneamento, p. 223.

${ }^{15}$ BORGES, p. 250; KOBAYASHI, "Eugenia," 315, 328-29.
} 
dência de infecção era de $100 \%$ "entre a população agrícola do País" (Figura 5). A missão da IHB seria a de pesquisar as regiões onde grassava a infecção responsável pela ancilostomiase, curar os habitantes infectados e criar as medidas sanitárias necessárias para "acabar com a poluição do solo". ${ }^{16}$ "Poluição do solo" referia-se à forma de contágio humano pelo Ancilóstomo (Ancylostoma duodenale ou Necator Americanus, parasitas intestinais causadores da ancilostomíase; Necator era, de longe, o mais comum no Brasil). As larvas se desenvolvem em solo úmido (num espectro ideal de temperatura de 21 a 29 graus), penetrando na pele humana exposta (normalmente pés descalços), movendo-se para a corrente sanguínea e atingindo a maturidade no intestino delgado, consumindo 0,2 $\mathrm{ml}$ de sangue diariamente. As fêmeas adultas produzem milhares de ovos todo dia, que são expelidos nas fezes, prontos para se tornarem novas larvas. As latrinas concentram a matéria fecal e quebram o ciclo reprodutivo. Pessoas com infecções moderadas ou pesadas podem ter de 50 a 500 vermes e sofrer de anemia progressiva devido à perda contínua de sangue. Os cientistas da IHB envolvidos na pesquisa contra a ancilostomíase em São Paulo concluíram que "quase nenhum indivíduo acima de 8 anos de idade no Brasil rural [estava] livre da infecção por Ancilóstomo" e que a causa principal da infecção era contato com "solo poluído". A ancilostomíase não ocorria por causa do tipo de solo ou suprimento de água, mas sim "de acordo com a proximidade do indivíduo com o solo infectado" e, portanto, "atenção especial deve ser dada aos trabalhadores do solo". ${ }^{17}$

\footnotetext{
${ }^{16}$ ROSE, Wickliffe. International Health Commission First Annual Report. New York, The Rockefeller Foundation, 1913-1914, p. 11-12.

17 PAWLOSWSKI, Z. S., SCHAD, G. A, \& STOOT, G. T. Hookworm Infestation and Anemia. Geneva: World Health Organization, 1991, p. 3-26. HACKETT, "No. 7597 , Report on work for the relief and control of hookworm disease in Brazil from November 22, 1916 to December 31, 1920," 21 October 1921, Series 3. Box 112, 20, RG 5, RAC, RFA ; DARLING, S. T., SMILLIE, W. G., "Studies on Hookworm Infection in Brazil". Monograph of the Rockefeller Institute for Medical Research 14 (1921), p. 8, 37; SMILLIE, W. G., "Studies on Hookworm Infection in Brazil, 1918-1920". Monograph of the Rockefeller Institute for Medical Research 17 (1922), p. 3-4; ROSE, Wickliffe. International Health Board Seventh Annual Report. New York, The Rockefeller Foundation, 1920, p. 67-73.
} 


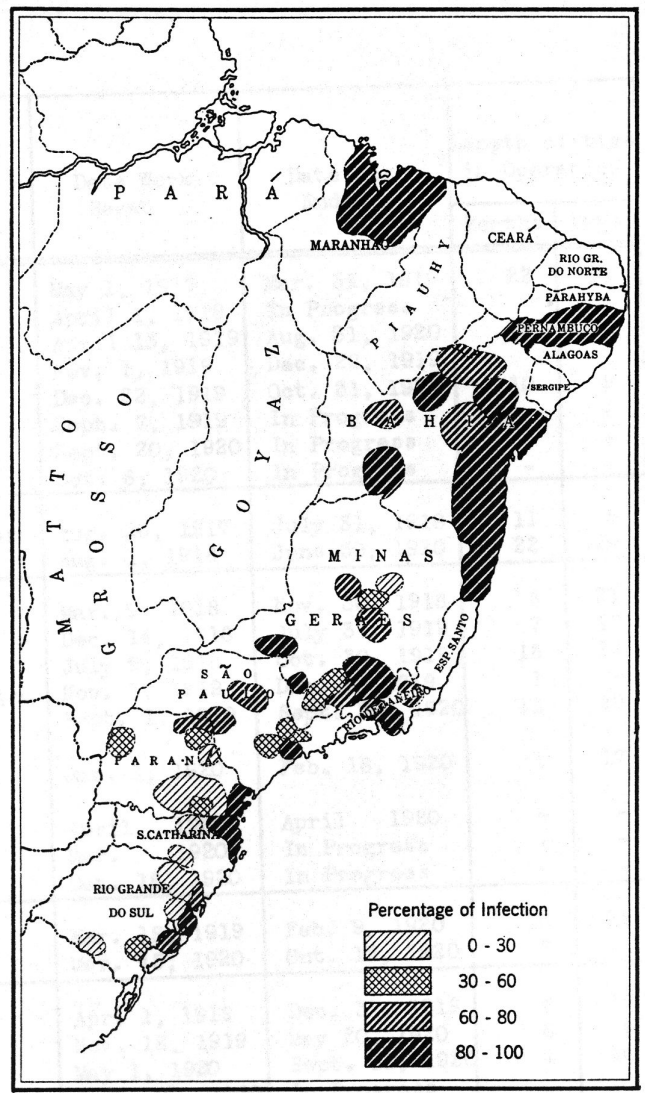

Figura 5: Distribuição de ancilostomíase no Brasil, segundo a Fundação Rockefeller. Fonte: HACKETT, "No. 7597, Report on work for the relief and control of hookworm disease in Brazil from November 22, 1916 to December 31, 1920," 21 October 1921, Series 3. Box 112, 20, RG 5, RAC, RFA, p. 6.

Durante o fim da década de 1910 e início de 1920, a IHB manteve seus esforços contra a ancilostomíase nas Américas e na Ásia. No Brasil, o primeiro país na América 
do Sul a receber a atuação da IHB, o número de países que colaboravam com os filantropos norte-americanos aumentou de três, em 1917, para oito, em 1921. Na metade da década de 1920, os gastos para a erradicação da ancilostomíase diminuíram, ao passo que houve grande aumento nos gastos de controle da malária e da febre amarela (Tabela 3) ${ }^{18} \mathrm{~A}$ atividade da IHB nos anos 20, em São Paulo, centrou-se em uma série de campanhas municipais para a erradicação da ancilostomíase e a criação de postos de saúde municipais. Uma contribuição duradoura da Fundação Rockefeller foi o apoio técnico e financeiro para a Faculdade de Medicina de São Paulo (FMSP), que iniciou suas atividades em 1915. Um contrato entre o Estado de São Paulo e a IHB levou à criação do Instituto de Higiene, dentro da FMSP e trouxe dois cientistas da FR, Samuel T. Darling (1918-1920) e Wilson G. Smillie (1920-22) para atuarem como diretores. ${ }^{19}$

\footnotetext{
${ }^{18}$ Vários trabalhos tratam das iniciativas de saúde pública da Fundação Rockefeller em outros lugares, ver vários ensaios na obra de Marcos Cueto, Missionaries of Science; Missionaries of Science; the Rockefeller Foundation and Latin America. Bloomington: Indiana University Press, 1994; HEWA, Soma. Colonialism, Tropical Disease and Imperial Medicine: Rockefeller Philanthropy in Sri Lanka. Lanham: University Press of America, 1995; PALMER, Steven. "The Demon That Turned into Worms": The Translation of Public Health in the British Caribbean, 1914-1920. História, Ciências, Saúde--Manguinhos 13, no. 3 (2006): 15-32; BIRN, Anne-Emanuelle. Marriage of Convenience: Rockefeller International Health and Revolutionary Mexico. Rochester: University of Rochester Press, 2006; HOEFTE, Rosemarijn. "The Difficulty of Unhooking the Hookworm: The Rockefeller Foundation, Grace Schneiders-Howard, and Public Health Care in Suriname in the Early Twentieth Century." In Health and Medicine in the Circum-Caribbean, 18001968, edited by Juanita de Barros, Steven Palmer and David Wright, 211-26. New York: Routledge, 2009; ANDERSON, Warwick. Colonial Pathogens: American Tropical Medicine, Race, and Hygiene in the Philippines. Durham: Duke University Press, 2006, p. 183-205; ETTLING, John. The Germ of Laziness: Rockefeller Philanthropy and Public Health in the New South. Cambridge: Harvard University Press, 1981; MARCUS, Alan I. "American Nationality and Hookworm in the United States, 1893-1909.” American Studies 30, no. 2 (1989): 103-21.

${ }^{19}$ MARINHO, Maria Gabriela S. M. C. O papel da Fundação Rockefeller na organização do ensino e da pesquisa na Faculdade de Medicina de São Paulo. Dissertação. Mestrado. Universidade Estadual de Campinas, 1993; FARIA, Lina Rodrigues de. "A Fundação Rockefeller e os Serviços de Saúde em São Paulo (1920-1930): Perspectivas Históricas." História, Ciências, Saúde--Manguinhos 9, no. 3 (2002): 561-90; FARIA,. "O Instituto de Higiene: Contribuição à História da Ciência e da Administração em Saúde em São Paulo.” Physis: Revista de Saúde Coletiva 9, no. 1 (1999): 175-208; CASTRO-SANTOS, Luiz A. de e Lina Rodrigues de FARIA. "A
} 
O equivalente paulista da IHB era a instituição de saúde pública mais progressista da América Latina, o Serviço Sanitário do Estado de São Paulo - SSESP. As atividades da IHB em São Paulo eram consideradas como as de uma divisão independente do SSESP (os problemas que podem ter resultado desse arranjo incluem a falta de "sanitarização do solo" e de construção de latrinas, discutidas a seguir). O SSESP começou a funcionar em 1892 com a missão de melhorar as condições de saúde primordialmente para os habitantes da capital do estado, em rápido processo de crescimento urbano. Em uma década, o Estado tinha mecanismos regulatórios, laboratórios e institutos de vacina e soro e um sistema de distritos e inspetores sanitários. No início do século XX, os oficiais sanitários haviam criado uma comissão para estudar e combater o tracoma, uma doença oftalmológica contagiosa que atingia milhares de trabalhadores rurais, e tinham iniciado um debate sobre os métodos de combate à ancilostomíase. Tentativas legislativas de acabar com a opção de atuação urbana da SSESP levaram à elaboração do Código Sanitário Rural de 1917, que criava postos de saúde nas cidades do interior (Figura 1), abria as fazendas aos inspetores sanitários, legislava sobre a construção de latrinas e caixas d'água em residências urbanas e rurais e criava um

Cooperação Internacional e a Enfermagem de Saúde Pública no Rio de Janeiro e São Paulo.” Horizontes, Bragança Paulista 22, no. 2 (2004): 123-50; FARIA, Lina. Saúde e Política: A Fundação Rockefeller e Seus Parceiros Em São Paulo. Rio de Janeiro: Editora Fiocruz, 2007. Para outras atividades da IHB no Brasil, ver SANTOS, Luiz Antonio de Castro. A Fundação Rockefeller e o estado nacional; História e política de uma missão médica e sanitária no Brasil. Revista Brasileira de História da População 6 (1989), p. 105-10; WILLIAMS, Steven C. "Nationalism and public health; the convergence of Rockefeller Foundation Technique and Brazilian Federal Authority during the time of Yellow Fever, 1925-1930". In: CUETO, Marcos, ed. Missionaries of Science; the Rockefeller Foundation and Latin America. Bloomington: Indiana University Press, 1994, p. 23-51; BLAKE, Stanley S. "The Medicalization of Nordestinos: Public Health and Regional Identity in Northeastern Brazil, 1889-1930." The Americas 60, no. 2 (2003): 217-48. O contexto brasileiro quanto ao saneamento está bem descrito em HOCHMAN, Gilberto, A Era do Saneamento: As Bases da Politica de Saúde Pública no Brasil. São Paulo: Editora Hucitec, ANPOCS, 1998. 
mecanismo regulatório para a aplicação do código de saúde no interior. ${ }^{20}$

Tabela 3 : Gastos da IHB no Brasil, por doença e gastos mundiais da IHB, 1913 - 1926 (em US\$, números arredondados). O controle de Malária exclui estudos de campo e experiências).

\begin{tabular}{c|c|c|c|c|c}
\hline Ano & $\begin{array}{c}\text { Controle e tratamento } \\
\text { de Ancilostomíase }\end{array}$ & $\begin{array}{c}\text { Controle de fe- } \\
\text { bre amarela }\end{array}$ & $\begin{array}{c}\text { Controle de } \\
\text { Malária }\end{array}$ & $\begin{array}{c}\text { Programas } \\
\text { municipais } \\
\text { de saúde }\end{array}$ & $\begin{array}{c}\text { G a s t o s } \\
\text { mundiais } \\
\text { da IHB }\end{array}$ \\
\hline $1913-14$ & 0 & 0 & 0 & 0 & 157731 \\
\hline 1915 & 0 & 0 & 0 & 0 & 333462 \\
\hline 1916 & 4780 & 0 & 0 & 0 & 506087 \\
\hline 1917 & 43309 & 0 & 0 & 0 & 578365 \\
\hline 1918 & 97031 & 0 & 0 & 0 & 1121863 \\
\hline 1919 & 155430 & 0 & 0 & 0 & 1436355 \\
\hline 1920 & 193561 & 0 & 0 & 0 & 1658573 \\
\hline 1921 & 129724 & 461 & 0 & 0 & 1696791 \\
\hline 1922 & 148189 & 470 & 0 & 12514 & 1868479 \\
\hline 1923 & 45827 & 99838 & 0 & 10708 & 2482903 \\
\hline 1924 & 47338 & 515421 & 31177 & 19313 & 2699802 \\
\hline 1925 & 24134 & 370392 & 32542 & 29240 & 3495117 \\
\hline 1926 & n.d. & 442185 & 12607 & 53372 & 3260525 \\
\hline Total & $\mathbf{8 8 9 3 2 3}$ & $\mathbf{1 4 2 8 7 6 7}$ & $\mathbf{7 6 3 2 6}$ & $\mathbf{1 2 5 1 4 7}$ & $\mathbf{2 1 2 9 6 0 5 6}$ \\
\hline
\end{tabular}

Fonte: ROSE, Wickliffe. International Health Board Eighth Annual Report. New York: The Rockefeller Foundation, 1921, p. 138-45; RUSSELL, Frederick F. International Health Board Thirteenth Annual Report. New York: The Rockefeller Foundation, 1926, p. 178-97.

\begin{abstract}
${ }^{20}$ RIBEIRO, Saúde Pública, p. 27-46, 183-201; BLOUNT, "Sanitary services", p. 137-51; BRUZO, Cristina. Em nome da saúde... da ordem e do progresso; discurso e prática dos médicos do Serviço Sanitário paulista no final do século XIX. Dissertação. Mestrado. Universidade Estadual de Campinas, 1989; CAMARGO, Ana Maria Faccioli. Os impasses da pesquisa microbiológica e as políticas de saúde pública em São Paulo (1892-1934). Dissertação. Mestrado. Universidade Estadual de Campinas, 1984. Para as politicas pós IHB, ver MERHY, Emerson Elias. A saúde pública como politica. São Paulo, 1920-1948. São Paulo: Hucitec, 1992, p. 67-159.
\end{abstract}


A Fundação Rockefeller e a campanha de eradicação da ancilostomíase...

\section{Pesquisa no Estado e a Campanha de erradicação da ancilostomiase}

Em 1917, a IHB da Fundação Rockfeller aceitou um convite do estado de São Paulo para trabalhar na erradicação da ancilostomíase e iniciou um levantamento no Estado. Entre dezembro de 1917 e fevereiro de 1918, um time de cientistas e assistentes brasileiros (treinados e supervisionados pela IHB) viajaram pelo Estado para determinar os niveis de infecção pelo Ancilóstomo, as características do solo e as instalações sanitárias. A amostragem de onze cidades e duas fazendas de café revelou que quase $59 \%$ das 8.570 pessoas examinadas estavam infectadas e que mais de 6.600 não dispunham de latrinas (Figura 6). Mais de $77 \%$ dos trabalhadores agrícolas, que passavam a maior parte da vida de pés descalços em fileiras de café, sem latrinas, apresentaram Ancilóstomos. Dada à falta de latrinas para os trabalhadores do café notaram os pesquisadores - ao defecar nos cafezais, eles acabavam introduzindo larvas de Ancilóstomo no solo e, dessa forma, continuamente se reinfectavam. A sombra dos pés de café, sob a qual os trabalhadores provavelmente defecavam, permitia que ovos se desenvolvessem e larvas crescessem e penetrassem no corpo de outros trabalhadores. Isso transformava o tratamento médico em perda de tempo, a menos que fossem tomadas medidas para melhorar o saneamento do campo. Diante disso, para facilitar o levantamento, as câmaras municipais passaram a fornecer hospedagem e espaços para laboratórios e assistentes de campo passaram a distribuir panfletos e a convidar a população rural para palestras (22 palestras atraíram cerca de 7.700 pessoas) e para visitas ao laboratório, onde havia uma exposição dos diferentes tipos de vermes. Uma palestra pública noturna era anunciada antes da chegada do grupo de pesquisadores, para discutir o papel da IHB e a transmissão e tratamento da ancilostomíase. A equipe fornecia vasilhames numerados aos interessados que depois os devolviam com amostras de fezes. Um tratamento gratuito com óleo de erva 
de Santa Maria (Chenopodium ambrosioides) era dado a cada pessoa que estava infectada. ${ }^{21}$

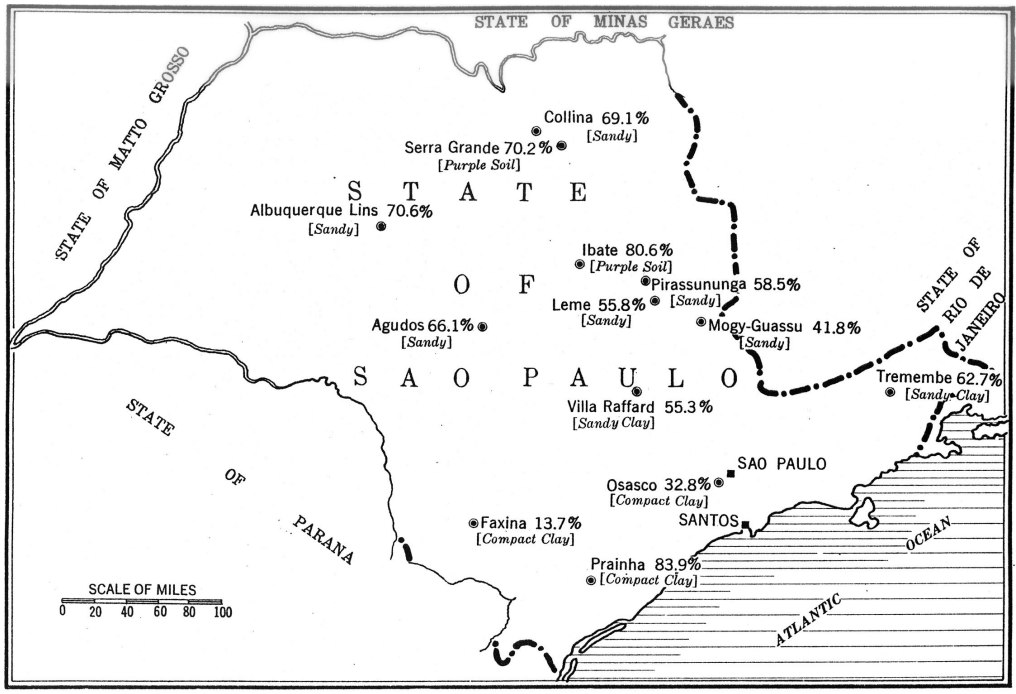

Figura 6: Taxa de infecção no estado de São Paulo; fonte: HYDRICK, J. L. "No. 7468, Hookworm infection survey of the State of São Paulo, Brazil, from December 1, 1917, to February 28, 1918", 9 August 1919, series 2, Box 23, Folder 135, RG 5, RAC, RFA, p. 28

A IHB abriu o primeiro de uma série de postos de erradicação da ancilostomíase perto de São Paulo logo após o término da pesquisa (Tabela 4). Guarulhos, a 19 quilômetros da capital, tinha fácil acesso - o suficiente para que sua inauguração em 17 de março de 1918 atraísse a elite médica e política de São Paulo, levada até a pequena cidade (de 500 habitantes) por um trem especial. Os jornais paulistas publicaram os discursos e deram detalhes sobre a unidade

${ }^{21}$ HYDRICK, J. L. "No. 7468, Hookworm infection survey of the State of São Paulo, Brazil, from December 1, 1917, to February 28, 1918”, 9 August 1919, series 2, Box 23, Folder 135, RG 5, RAC, RFA; ROSE, Wickliffe. International Health Board Fifth Annual Report. New York, The Rockefeller Foundation, 1918, p. 88-9, 104-5. 
A Fundação Rockefeller e a campanha de eradicação da ancilostomíase...

de erradicação da ancilostomíase da IHB. Durante o mês de março de 1918, os funcionários brasileiros, treinados pela IHB, examinaram cerca de 700 pessoas na região de Guarulhos e descobriram que apenas $37 \%$ estavam infectados pelo Ancilóstomo - índice provavelmente muito abaixo das expectativas da IHB. Em contraste com isso, em novembro de 1917, a SSESP, como parte de sua colaboração com a IHB, abriu um posto de erradicação da ancilostomíase em Iguape, uma cidade costeira relativamente inacessível e com altos índices de infecção (acima de 90\%). Os funcionários da IHB sugeriram que os baixos índices de infecção, no caso de Guarulhos, tinham relação com sua proximidade da capital. Eles esperavam que o próximo município escolhido fosse em uma região do estado "mais fortemente infectada". ${ }^{22}$

Tabela 4 : Censo da IHB, índices de infecção e duração dos esforços de erradicação do ancilóstomo em municípios de São Paulo, 1917-1924. Cinco fazendas excluídas. Os números de municípios correspondem à Figura 2

\begin{tabular}{|c|c|c|c|c|c|}
\hline \multirow[t]{2}{*}{ Município } & \multirow{2}{*}{$\begin{array}{c}\text { População } \\
\text { segundo o } \\
\text { censo da IHB }\end{array}$} & \multirow[t]{2}{*}{$\begin{array}{l}\% \text { de infectados - } \\
\text { todos os vermes }\end{array}$} & \multirow[t]{2}{*}{$\begin{array}{l}\text { \% de infectados } \\
\text { - ancilóstomo }\end{array}$} & \multicolumn{2}{|c|}{ Duração } \\
\hline & & & & meses & dias \\
\hline 1. Guarulhos & 4088 & 83 & 57 & 8 & 21 \\
\hline 2. Brodósqui & 9820 & 83,8 & 70,6 & 7 & 16 \\
\hline 3. Atibaia & 16774 & 84,5 & 52,7 & 15 & 21 \\
\hline 4. Nazaré & 3365 & 90,7 & 34,1 & 2 & \\
\hline 5. São Simão & 23915 & 86,6 & 79,2 & 13 & \\
\hline 6. Orlândia & 34919 & 80,9 & 67,3 & 22 & 8 \\
\hline 7. Cravinhos & 15856 & 70,1 & 52 & 8 & 20 \\
\hline 8. Piracaia & 9262 & 70,9 & 34,4 & 6 & \\
\hline 9. Viradouro & 10164 & 64,4 & 55,8 & 11 & 20 \\
\hline
\end{tabular}

continua

22 HACKETT, L. W. "No. 7339, Report on work for the relief and control of uncinariais in Brazil form the year ending December 31, 1917", 20 May 1918, Series 2, Box 23, Folder 135, 24-5, RG 5, RAC, RFA; HACKETT, "Report on the work of the International Health Board in Brazil for the quarter ending March 31, 1918”. 17 April 1918, Series 3, Box 111, 2, RG 5 RAC, RFA. 


\begin{tabular}{c|c|c|c|c|c}
\multicolumn{9}{c}{ continuação } \\
\hline 10. Sertãozinho & 24329 & 76.2 & 60,2 & 17 & 5 \\
\hline 11. Bragança & 33016 & 77,4 & 54,2 & 24 & \\
\hline 12. Tietê & 14156 & 84,1 & 67,2 & 18 & \\
\hline 13. Jardinópolis & 14925 & 89,3 & 79,2 & 18 & \\
\hline 14. Araraquara & 15979 & 92,1 & 86,6 & 18 & 19 \\
\hline 15. Piracicaba & 15690 & 88,4 & 77,6 & 12 & 15 \\
\hline 16. Angatuba & 4304 & 84,0 & 60 & 9 & \\
\hline
\end{tabular}

Fonte: STRODE, George K. "Report of the activities of the International Health Board in Brazil and Paraguay for the period from the $1^{\text {st }}$ of January to the $31^{\text {st }}$ of December, 1923 ". 5 March, 1924. Series 3, Box 108, RG, 5, 77-8, RAC, RFA; STRODE, George K. "Annual report for the year ending December $31^{\text {st }}, 1924$, covering work of the International Health Board in the United States of Brazil and the Republic of Paraguay". 9 February 1925, Series 3, Box 108, RG 5, 60-1 RAC, RFA.

A oportunidade para a IHB trabalhar em tais regiões veio logo após o fechamento da unidade de Guarulhos. Entre 1918 e 1924, a IHB promoveu esforços para a erradicação do Ancilóstomo em quatorze outros municípios e cinco fazendas (Figura 1, Tabela 4). Em Atibaia e Brodósqui, os funcionários da IHB e as elites cafeeiras tinham o desejo comum de melhorar a saúde e produtividade dos trabalhadores do café. A equipe de Guarulhos chegou em Brodósqui em dezembro de 1918 e usou uma casa, com eletricidade, água e pasto para os animais fornecidos por funcionários municipais. A principal atração de Brodósqui era que o município era "composto inteiramente por cafezais", o que os funcionários da IHB afirmavam "facilitar o trabalho de coleta de dados estatísticos" em comparação a um município com uma população dispersa. Mais de $70 \%$ do município estava infectado com ancilóstomos, mas o tratamento revelou-se ser mais dificil do que constatar e quantificar a infecção. Dos 9.600 exames, 5700 pessoas, ou cerca de $60 \%$, foram tratadas. ${ }^{23}$

\footnotetext{
${ }^{23}$ HACKETT, "No. 7469. Report on Work for the Relief and Control of hookworm disease in Brazil, from November 22, 1916, to December 31, 1918". 16 August 1919, Series 2, Box 24, Folder 149, 57, RG 5, RAC, RFA.
} 
Quando a IHB se preparava para encerrar suas atividades em Brodósqui em julho de 1919, "os mais influentes cafeicultores" do municipio fizeram uma reunião e solicitaram ao diretor de campo da IHB para "ficar permanentemente no municipio para manter o novo nível sanitário". A cidade e seus cafeicultores contribuiriam com US\$500 por mês (US\$250 para salário de médicos e U\$250 para manutenção do pessoal e remédios). A infraestrutura seria usada "para o tratamento dos trabalhadores que chegassem aos cafezais e para inspeção de latrinas". O diretor da IHB no Brasil, Lewis Hackett, chamou isso de "o germe da ideia de agência municipal de saúde" - uma forte reivindicação, considerando-se a grande importância do trabalho de saúde municipal para a IHB. Isto tornou a unidade de Brodósqui "a primeira agência municipal de saúde a ser mantida por fundos locais", o que não era pouca coisa. ${ }^{24}$

Em Atibaia, um município cafeicultor do norte do estado de São Paulo, a erradicação da ancilostomíase começou em julho de 1918 e resultou no tratamento de 7.200 pessoas, das 8.300 com infecção confirmada. Os funcionários da IHB observaram orgulhosos que um jornal de Atibaia "imprimiu com detalhes todas as palestras realizadas" sobre a erradicação do Ancilóstomo e também "publicou diversos artigos sobre saúde pública e higiene". A importância da unidade da IHB em Atibaia se deve ao fato de ter se tornado conhecida como "Laboratório das Fazendas", cujo propósito era "ir de fazenda em fazenda e tratar os trabalhadores em cada uma delas". Os fazendeiros forneciam o transporte e acomodações para os sanitaristas da IHB à medida que eles viajavam entre as propriedades. ${ }^{25}$ Ao menos algum incentivo para criar um programa de erradicação da ancilostomíase específico para

\footnotetext{
${ }^{24}$ HACKETT, "Report on Work for the Relief and Control of hookworm disease in Brazil for the quarter ending September 30, 1919". 1919, Series 3, Box 112, 1819, RG 5, RAC, RFA; Idem, No. 7537, "Report on work for the relief and control of hookworm disease in Brazil from November 22, 1916, to December 31, 1919," 24 December 1920, Series 3, Box 112, 18-19, RG 5, 21, RAC, RFA; Hackett to Wickliffe Rose [IHB director], 29 August 1919, Series 1.2, Box 78, Folder 1110, RG 5 RAC, RFA.

${ }^{25}$ HACKETT, “No. 7469”, p. 60-6; Idem, “No. 7537,” p. 19-20
} 
as propriedades cafeeiras veio de um pedido de uma associação de cafeicultores ao diretor Hackett, pedindo que a IHB "adaptasse seus serviços às grandes fazendas de café". Hackett afirmou que esse grupo da elite de produtores "ofereceu cooperação financeira que cobria um percentual considerável das despesas envolvidas". ${ }^{26}$

O "Laboratório das Fazendas" de Atibaia, após tratar os trabalhadores de diversas propriedades, mudou-se para Orlândia, a noroeste de Ribeirão Preto, o principal município produtor de café do estado de São Paulo, com 31,4 milhões de pés de café. O mesmo sistema de "Laboratório das Fazendas" deveria ser usado, mas os funcionários locais "insistiram tanto e demonstraram tamanho interesse em que todo o município fosse tratado que o plano de trabalho nas fazendas foi abandonado; o município foi então considerado como uma unidade de operação e uma campanha regular e intensiva foi realizada." O contrato aparentemente estipulava que os proprietários de terra de Orlândia forneceriam acomodações para o pessoal da IHB durante a campanha de erradicação da ancilostomíase em suas propriedades, fornecendo também acomodações e alimentação para a equipe da IHB na cidade. Em seu relatório bimestral, o diretor Hackett elogiou os funcionários de Orlândia, que pareciam "determinados a fazer de seu município um modelo aos outros" em São Paulo, "convidando mesmo as autoridades dos municipios vizinhos para encontrá-los e discutir os meios de combate às doenças mais comuns". Os funcionários de Orlândia, médicos, em sua maioria, também publicaram artigos nos principais jornais paulistas sobre questões de sanitarismo rural. ${ }^{27}$

$\mathrm{Na}$ maioria dos municipios em que atuou, a IHB teve dificuldades para convencer os habitantes rurais a participar

\footnotetext{
${ }^{26}$ HACKETT, "Quarter ending September 30, 1919", 5. Não pude confirmar a existência deste pedido nos arquivos da RFA.

${ }^{27}$ HACKETT, "No. 7597, Report on work for the relief and control of hookworm disease in Brazil from November 22, 1916 to December 31, 1920," 21 October 1921, Series 3. Box 112, 20, RG 5, RAC, RFA; Idem, "Report on work for the relief and control of hookworm disease in Brazil during the quarter ending March 31, 1920," 25 April 1920, Series 3. Box 112, 14, RG 5, RAC, RFA.
} 
dos curiosos rituais de coleta de amostras fecais. Em Orlândia, mais de 14.000 habitantes se recusaram ao tratamento, levando a IHB a considerar que havia mais de 17.000 "não curados permanecendo na área”. Em Cravinhos, houve 6.314 recusas de tratamento - mais que o número de pessoas dispensadas ou curadas. Situação semelhante aconteceu em Angatuba, "uma das mais atrasadas" das municipalidades de São Paulo, onde houve "dificuldades" no interior, por conta de "ignorância e desconfiança da população" e "antagonismo dos charlatães locais". Talvez "ignorância" e "antagonismo" eram nada mais que ceticismo dos trabalhadores rurais para com estrangeiros coletando amostras de fezes. ${ }^{28}$

Um outro problema nos esforços de erradicação do Ancilóstomo da IHB era a falta de construção de latrinas. A IHB deixara essa medida preventiva-chave à SSESP, e não dispunha dos meios para exigir que as latrinas fossem construídas. No contexto das ênfases expressas pela IHB para eliminar as causas da ancilostomíase, como indicado em diversos relatórios, a não construção de latrinas nas áreas rurais era inesperada. Em alguns municipios, a construção de latrinas tornou-se uma prioridade para os cargos permanentes que se seguiram aos esforços de erradicação do Ancilóstomo (ver abaixo e Tabela 5). O médico brasileiro - treinado pela IHB -, Mario Pernambuco, observou que "praticamente nenhum resultado foi obtido com relação à construção de privadas" em Orlândia, e das 5.100 casas inspecionadas, somente 600 tinha latrinas (a maioria das quais, provavelmente em áreas urbanas). Em Cravinhos, uma lei municipal obrigava a construção de latrinas na cidade e no campo, mas durante o período de atividades da IHB somente oito foram construídas - todas em áreas urbanas. Em outros

${ }^{28}$ PERNAMBUCO, Mario. "Report on work for the relief and control of hookworm disease in Orlândia", In HACKETT, "Annual report for Brazil, January $1^{\text {st }}$ to December 31 $1^{\text {st }} 1921$." 24 March 1922. Series 3, Box 112, 248, 256, RG 5, RAC, RFA (daqui em diante referido como "Annual Report 1921".) STRODE, George K. "Annual report for the year ending December 31 $1^{\text {st }} 1924$, covering work of the International Health Board in the United States of Brazil and the Republic of Paraguay". 9 February 1925, Series 3, Box 108, 158, RG 5, RAC. RFA (daqui em diante citado como "Annual report, 1924). 
municípios, os resultados da construção de latrinas, uma medida preventiva chave no combate ao Ancilóstomo, foram também desanimadores. Duas latrinas foram construídas em áreas rurais de Angatuba, mas nenhuma foi feita em Jardinópolis, mesmo que $86 \%$ das 2.470 casas não dispusesse de nenhuma forma de "instalação sanitária". Tietê, um dos últimos municípios no esforço de erradicação, foi uma exceção, com a construção de 137 latrinas. ${ }^{29}$

Mario Pernambuco, um médico e inspetor de campo brasileiro da IHB, afirmou que os colonos ficaram desconfiados: "fallou-se em imperialismo americano, em propaganda protestante americana, em recrutamento para a guerra, etc.", porém, logo depois, Pernambuco escreve, "não podemos attender aos numerosos convites que nos são dirigidos por grande numero de muncípios". Os fazendeiros também estavam desconfiados. Não foi por acaso que Pernambuco, em palestra no Instituto de Higiene (reproduzida na Revista da Sociedade Rural Brasileira, porta-voz dos fazendeiros de café), falou sobre a "plena convicção de que o saneamento rural é a condição primordial, condição sine qua non, para o desenvolvimento" das propriedades rurais de São Paulo. ${ }^{30}$

As plantações de café com uma população rural relativamente densa em Brodósqui, fator necessário para a manutenção e a colheita do café, atraiu a IHB para o município. Mas, ao contrário da imagem das elites pró-imigração e antisaúde pública, os fazendeiros ajudaram a manter a estrutura de saúde pública. Em maio de 1919, Francisco Corrêa, o terceiro maior cafeicultor de Brodósqui (e um coronel), postou uma carta para os funcionários da IHB declarando sua gratidão pela melhoria na saúde dos seus trabalhadores residentes. É notável como Corrêa reproduziu as ideias da

\footnotetext{
${ }^{29}$ PERNAMBUCO, Mario. "Report on work for the relief and control of hookworm disease in Cravinhos." In HACKETT, "Annual report, 1921", 241; STRODE, "Annual report, 1924", 177, 189, 199, 209, 219.

${ }^{30}$ PERNAMBUCO, Mario. "O saneamento rural", Revista da Sociedade Rural Brasileira 19-20, 1922, p. 41. Pernambuco, o diretor estaudal da Comissão Rockefeller, fez esta palestra no Instituto de Higiene "sob auspicios da SRB" em dezembro de 1921 
A Fundação Rockefeller e a campanha de eradicação da ancilostomíase...

época, tanto de Monteiro Lobato quanto de Belisário Penna, antecipando o discurso do "novo homem" que foi parte da propagada, anos depois, de Fontoura para vender o seu produto farmacêutico: "É triste, mas é real verdade, foi preciso que homens humanitarios viessem do outro lado do oceano condoer-se dos Jécas." Corrêa tambem relatou o que um colono da sua fazenda teria comentado: "já é 'fortuna' ter adquirido novamente a sua saude, que hoje sendo outro homem (quem o diz é um homem de 68 anos) e que estava pedindo a Deus que o alliviasse com brevidade deste mundo...hoje é um trabalhador que compete com um moço de 30 annos." Outra carta, de um administrador de uma fazenda de café, relatou como "a maioria dos nossos colonos eram anemicos, enfraquecidos, e facilmente attingidos por enfermidades que lhes acarretavam despezas com medico e pharmacia...Faltava-lhes a coragem para o trabalho. Ao menor esforço que faziam, ficavam prostrados. Homens que poucos mezes antes eram verdadeiros Hercules, não tinham mais força para pôr um sacco em uma carroça". Quando a "Comissão Rockefeller" chegou em Orlândia, tudo mudou. Alguns colonos resistiram ao tratamento, mas outros aceitaram e a saúde deles melhorou, até que conseguiram sobreviver ao sarampo logo depois: "os nossos pobres colonos, alegres, fortes, vivem abençoando a Rockefeller, a mais humanitaria instituição do mundo!"31

Esses tipos de discursos apareceram em outras publicações na mesma época. A Revista dos Fazendeiros (portavoz da oligarquia do café) publicou textos apoiando o enfoque sanitarista da IHB. A mesma revista que havia publicado textos favorecendo a importação de trabalhadores para café enfatizava, em 1920, em artigo originalmente publicado no Estado de São Paulo, as interligações entre o pensamento eugênico e o movimento sanitarista:

${ }^{31}$ Carta de Francisco Correa a Mario Pernambuco, 3 de maio de 1919, reproduzida em Revista da Sociedade Rural Brasileira, 19-20, 1922, p. 44; carta de Primo Azzi a Mario Pernambuco, 21 de julho de 1920, reproduzida em Revista da Sociedade Rural Brasileira 19-20, 1922, p. 43. 
Agora é que se estão descubrindo as qualidades do trabalhador brasileiro: agora não é mais o paria como ha annos atras: o ultimo, o mais mal pago, forçado a morar nas peores e mais mal collocadas casas das fazendas, o desprezado sempre, cedendo o melhor para o estrangeiro que aqui apportava sadio e bem alimentado. Antes tarde do que nunca. O que falta ao nosso caboclo e ao nosso preto é bom passadio e certa hygiene para ter disposição para o trabalho, desafiando, traço mesmo, qualquer outra raça na resistência e na prestaza para qualquer serviço ${ }^{32}$.

Outro texto, publicado em 1922, discute os sintomas de amarelão, descrevendo a doença como "um dos maiores inimigos da nossa agricultura e um grande obstaculo ao desenvolvimento do nosso paiz", ainda indicando o produto Ankilostomina Fontoura (Figura 4) para o seu tratamento. ${ }^{33}$

\section{Da erradicação do ancilóstomo aos postos de saúde municipais permanentes}

Um dos fundamentos da filantropia da IHB em São Paulo era o estabelecimento de unidades de saúde municipais (Tabela 5). Em 1921, o estado de São Paulo concordou em equiparar os fundos oferecidos pela IHB e pelos municipios, no sentido de estabelecer e manter um posto de saúde municipal permanente em duas cidades. De acordo com o contrato datado de setembro de 1921, de um orçamento global de US\$6.750, o municipio forneceria US\$2.500, o Estado, US\$3.125 e a Fundação Rockfeller, US\$1.125. Até ao final de 1921, oito municipios solicitaram para a IHB campanhas intensivas de erradicação do ancilóstomo e unidades permanentes de saúde, "para manter os resultados da campanha". Os interesses locais também estavam presentes beste caso. A câmara municipal de Viradouro mandou um telegrama ao diretor Hackett, solicitando que a IHB começasse uma

\footnotetext{
${ }^{32}$ Problemas de hygiene rural, Revista dos fazendeiros 3(1920), s.p.

${ }^{33} \mathrm{O}$ amarelão e seu tratamento, Revista dos fazendeiros 5 (1922), s.p. 
A Fundação Rockefeller e a campanha de eradicação da ancilostomíase...

campanha na cidade e garantindo fundos municipais para um posto de saúde permanente. A campanha de erradicação do ancilóstomo começou em Viradouro em Novembro de 1921, mas nenhum posto permanente foi implantado. ${ }^{34}$

Tabela 5: Postos de saúde municipais estabelecidos pela IHB em São Paulo, 1922-1926. Os números dos municípios correspondem à figura 2

\begin{tabular}{c|c|c}
\hline Município & \multicolumn{2}{c}{ Data do estabelecimento } \\
\hline & Mês & Ano \\
\hline Orlândia & 2 & 1922 \\
\hline Sertãozinho & 6 & 1922 \\
\hline Araraquara & 6 & 1923 \\
\hline Piracicaba & 12 & 1923 \\
\hline Tietê & 1 & 1925 \\
\hline Santa Rita do Passaquatro (17) & 2 & 1925 \\
\hline Itú (18) & 3 & 1925 \\
\hline Espírito Santo do Pinhal (19) & 6 & 1925 \\
\hline São José do Rio Preto (20) & 8 & 1926 \\
\hline Sorocaba (21) & 4 & 1926 \\
\hline Cândido Mota (22) & & 1926 \\
\hline Taquaritinga (23) & & 1926 \\
\hline
\end{tabular}

Fonte: STRODE, George K. "Annual repport for 1925 covering work of the International Health Board in the United States of Brazil, the Republic of Argentina and the Republic of Paraguay". 12 February 1926, Series 3, Box 109, RG 5, 64 RAC, RFA.; STRODE [ Annual Report 1926]. Series 3, Box 109, RG5, 42-52, RAC, RFA.

Em 1923, Orlândia e Sertãozinho se tornaram os primeiros municípios com postos de saúde permanentes apoiados pela IHB, em São Paulo. Hackett observou, em 1921, que as autoridades estatais concordaram que a IHB selecionaria "um dos municípios economicamente importantes" em São

34 HACKETT, "Annual report, 1921", 134; Hackett to Rose, 21 October 1921, series 1.2, Box 113, Folder 1536, RG 5, RAC, RFA. A quantia oferecida foi de até $\$ 500$ réis, ou US $\$ 0,125$, anualmente, por habitante, o que se imaginava gerar de 6 a 10 mil dólares por ano. Mario Pernambuco afirmava que a IHB recebeu 18 convites em 1921 (PERNAMBUCO, "O saneamento básico", p. 41). 
Paulo, e não deve ter sido surpresa que dois municípios cafeicultores fossem escolhidos. O trabalho de saúde municipal era uma tarefa importante para a IHB e representava um objetivo de longo prazo na filantropia de saúde pública. $\mathrm{O}$ diretor da IHB, Wickliffe Rose, escreveu entusiasmado para Hackett, em 1921:

Você tem agora as mesmas oportunidades no Brasil que aquelas que tentamos usar neste país [EUA]. Esta é uma oportunidade para trabalho criativo. Um bom programa de saúde pública é uma coisa a ser delineada. Estamos no começo. O primeiro esforço deve ser na natureza de um experimento. Devemos começar modestamente, movermo-nos deliberadamente e medir com cuidado cada passo. ${ }^{35}$

Em meados da década de 1920, o Brasil foi o único país estrangeiro além do Canadá a receber fundos significativos da IHB para o trabalho em saúde pública. Em 1926, a IHB apoiava onze unidades de saúde pública municipais em São Paulo e várias outras em Minas Gerais. Coletivamente, as onze unidades paulistas tiveram uma contribuição impressionante: examinaram 2.100 estudantes, realizaram 42.800 inspeções sanitárias, construíram 1.275 latrinas, fizeram 42.860 exames laboratoriais, aplicaram 95.050 vacinas contra sarampo, forneceram 38.631 tratamentos contra ancilostomose e 69.770 tratamentos para tracoma. Mas o desempenho era desigual. No caso da construção de latrinas, somente 15 foram construídas em Espírito Santo do Pinhal, 40 em Itú e 377 em Taquaritinga. ${ }^{36}$

Como Wickliffe Rose sugeriu a Hackett, o trabalho municipal de saúde era dificil e complexo. Os médicos brasileiros recebiam algumas semanas de treinamento no Instituto de Higiene, na capital, apoiado pela IHB, e então começavam a trabalhar na cidade específica sob supervisão da IHB. Flutuações no apoio municipal indicavam o fim do posto de

${ }^{35}$ Hackett to Rose, 9 July, 1921, Series 1.2, Box 113, Folder 1536, RG 5, RAC, RFA; Rose to Hackett, 21 August, 1921. Series 1.2, Box 113, Folder 1536, RG 5 , RAC, RFA.

${ }^{36}$ RUSSELL, Frederick F. International Health Board Thirteenth Annual Report. New York, The Rockefeller Foundation, 1926, p. 186-87; STRODE, "Annual report, 1926", 1927, Series 3, Box 109, 52, RG 5, RAC, RFA. O Total dos gastos municipais da IHB nos Estados Unidos em 1926 foi de US\$167.500. 
saúde. Sertãozinho, a cerca de 25 quilômetros de Ribeirão Preto, foi um dos primeiros a receber um posto de saúde permanente. Mas, em 1926, George Strode, o substituto de Hackett, reclamava que os funcionários municipais "perderam completamente o interesse no trabalho municipal de saúde" e Sertãozinho sairia dos programas da IHB em $1927 .{ }^{37} \mathrm{Um}$ exemplo semelhante é o município de Tietê, onde o trabalho de saúde municipal começou no início de 1925 após uma intensa campanha de erradicação do ancilóstomo. O posto municipal de saúde fechou no fim de março de 1926 em função da "falta de cooperação financeira por parte do município", de acordo com o diretor Strode. ${ }^{38}$ Além da falta de apoio municipal, outro problema do trabalho municipal de saúde, de acordo com os funcionários da IHB, era a percepção pública do posto de saúde como um lugar de atendimento gratuito. Reclamava-se que o imenso número de casos de tracoma, doenças venéreas e ancilostomíase ocupavam recursos humanos e desviava os esforços necessários para educação, exames escolares de saúde, publicidade e inspeções sanitárias - consideradas a linha de ação adequada para um posto de saúde municipal da IHB. ${ }^{39}$

\section{Descrições da vida de colono nas fazendas de café paulistas}

Durante o processo de visita às fazendas, coletando amostras de fezes, e tratando as vitimas de ancilostomíase, os funcionários da IHB fizeram breves observações por escrito da vida rural nas propriedades cafeeiras. Apesar do contato diário com trabalhadores rurais, especialistas como Wilson

\footnotetext{
37 STRODE, "Annual report, 1926", p 49. Idem. "Report of the activities of the International Health Board in Brazil and Paraguay for the period from the $1^{\text {st }}$ January to the $31^{\text {st }}$ December 1923", 5 March 1924, Series 3, Box 108, 101-102, 233-37. RG 5, RAC, RFA.

${ }^{38}$ STRODE, "Annual report for 1925 covering the work of the International Health Board in the United States of Brazil, the Republic of Argentina and the Republic of Paraguay", 12 February 1926, Series 3, Box 109, 75-6, RG 5, RAC, RFA; Idem, “Annual report 1926," 38.

${ }^{39}$ STRODE, “Annual report 1925”, p. 66-69.
} 
G. Smillie e Samuel Darling deixaram poucos relatos escritos da situação sócio-econômica que criou as condições para a infecção pelo ancilóstomo. Smillie, que passou mais de um ano estudando a ancilostomose e o sanitarismo, escreveu duas cartas muito vividas ao diretor da IHB, Wickliffe Rose, nas quais descreveu as diferenças da vida rural para os colonos e para os proprietários. Enfatizando as limitações de oportunidades para mobilidade ascendente para os colonos, Smillie afirmou que, durante os "anos bons", a renda de "grandes famílias" podia chegar até US\$ 500, combinando rendimentos do trabalho nos cafezais, o cultivo do milho, arroz e, às vezes, algodão, e a venda de porcos e frangos. Os colonos recebiam todos os lucros dos cereais, mas os proprietários mantinham um terço dos recebimentos de outros produtos agrícolas. Smillie enfatizou que os colonos tinham altas dividas para com os proprietários, em função dos altos preços cobrados no monopólio da loja da fazenda. Isso evitava que os colonos abandonassem a propriedade cafeicultora. ${ }^{40}$

Mesmo se os colonos conseguissem pagar as dividas e sair da propriedade, eles enfrentavam problemas estruturais no tocante ao crédito e ao mercado imobiliário rural. Smillie afirmou que havia uma falta "de pequenas parcelas de terra que fossem vendidas em pequenos lotes", bem como uma escassez de bancos, que impedia que os colonos obtivessem empréstimos para entrar na agricultura comercial. Não há dúvida que esses impedimentos estruturais para a aquisição de terra produziam a tensa situação rural na região de Ribeirão Preto observada por Smillie, que registrou temer a chegada de "modernas ideias europeias" e de "modernas teorias perturbadoras" ao sul do Brasil:

\footnotetext{
${ }^{40}$ Wilson G. Smillie to Rose, $1^{\text {st }}$ April, 1919. Series 1.2 , Box 79, Folder 1114, RG 5 RAC, RFA. De acordo com Holloway, os 500 dólares seriam 50 dólares a menos que uma estimativa de 1903 para renda bruta de uma família de colonos com quatro membros (equivalentes a mais de 2000 pés de café cuidados anualmente). HOLOWAY, Imigrantes, p. 132. 
A Fundação Rockefeller e a campanha de eradicação da ancilostomíase...

As pessoas são tão ignorantes, tão excitáveis, e sentem seu fardo de forma tão grande, que só é necessária uma liderança organizada para virar todo o sistema de trabalho de cabeça para baixo, e tomar a terra dos grandes proprietários e dividila entre o povo. ${ }^{41}$

Ao longo do início de 1919, o colega de Smillie, Samuel Darling, conduziu uma série de experiências com o ancilóstomo nos cafezais de Brodósqui e Atibaia. As anotações de Darling sobre esses experimentos referem-se a quatro propriedades cafeicultoras e contêm, primordialmente, os nomes dos objetos de pesquisa, sua contagem de vermes e o tempo gasto em cada fazenda "típica". Darling descreveu diferenças nas acomodações dos colonos entre as várias propriedades. Na Fazenda Santa Rosa, em Brodósqui, as casas dos colonos eram de tijolos recobertos por massa, e com telhas de barro. Duas famílias dividiam cada casa, e cada família tinha porcos, frangos e uma horta ocasional, fazendo Darling observar, nas suas anotações, que tais padrões de vida eram "muito maiores do que qualquer outra fazenda" que ele já visitara. Nessa propriedade os alimentos eram "mais abundantes e em maior variedade" porque os colonos comiam ovos e carne de frango duas ou três vezes por semana. Em contraste, na Fazenda Bom Jardim em Brodósqui, onde a maioria dos trabalhadores era japonesa e vivia em casas de sapé e chão batido, os recém-chegados comiam somente arroz e verduras, acrescentando, com o tempo, feijão e fubá (um "costume brasileiro"). As condições podiam variar enormemente mesmo no interior de cada propriedade. Na Fazenda Santa Maria, em Brodósqui, onde predominavam os imigrantes italianos, algumas das 200 casas de colonos eram construídas de tijolos, com telhas de barro, enquanto outras "eram construídas de forma muito pobre, viradas para o chiqueiro e o pasto".

Nas fazendas, diferenças significativas existiam também com relação à higiene, saúde e condições de vida dos colonos. Na Fazenda Santa Rosa, citada anteriormente pela boa dieta dos colonos, mais da metade das crianças sofria de tracoma, e quase todas as famílias tinham pelo menos um

${ }^{41}$ Ibid. 
membro debilitado por essa doença contagiosa. Darling contou diversos jovens adultos que não podiam trabalhar nos cafezais pela perda da visão e dor causadas pelo tracoma. Em outra fazenda, Darling relatou que seu dono, o presidente da Câmara Municipal local, tinha um "excelente" sistema de fornecimento de água encanada para as casas a partir de fontes naturais, e tinha também recentemente construído latrinas com fossas, mas tinha "grande dificuldade em fazer com que as pessoas [os colonos] usassem-nas". Na Fazenda Jaboticabal em Atibaia, na qual os brasileiros dominavam a força de trabalho, Darling elogiou o sistema de abastecimento de água (encanada, a partir de fontes fechadas), mas notou que quatorze familias de colonos usavam um riacho próximo para lavar a roupa e para fazer as necessidades. ${ }^{42}$

\section{Considerações finais}

A Diretoria Internacional de Saúde da Fundação Rockefeller trouxe uma campanha de erradicação da ancilostomíase aos cafezais de São Paulo no fim de 1917, e, em poucos anos, iniciou programas de saúde em doze municípios. Essa presença filantrópica na saúde pública levanta pelo menos três questões amplas: a interação entre as elites cafeicultoras e os funcionários da IHB, o processo de escolha de áreas para o trabalho de saúde pública e a falta de construção de latrinas.

Qual foi a extensão da interação entre os cafeicultores paulistas e os funcionários da IHB? As evidências apresentadas aqui sugerem que as elites do café forneciam apoio, inicialmente entusiástico, mas mais tarde oscilante em alguns casos, para atrair os funcionários da IHB para suas plantações. Os exemplos dos cafeicultores de Brodósqui e dos "Laboratórios das Fazendas" sugerem um retrato das eli-

\footnotetext{
${ }^{42}$ DARLING, Samuel L. "Report on the field research work on hookworm infection of the Instituto de Hygiene, São Paulo" 24 May, 1920, Series 2, Box 23, RG 5 , RAC, RFA. 
tes apoiando as medidas sanitárias rurais da IHB em suas propriedades, mas antagonizando a legislação de saúde pública. Talvez as elites tenham se aproveitado da filantropia estrangeira, sem um comprometimento de longo prazo para melhorar a saúde dos trabalhadores. Elas sabiam que poderiam controlar os funcionários da IHB dirigindo-os para lugares específicos e sabiam que poderiam fornecer e depois retirar seu apoio. As elites podem ter agarrado a oportunidade para ganhos de curto prazo - trabalhadores curados da ancilostomíase - em troca da abertura de suas fazendas para filantropos estrangeiros. Por exemplo, o editorial de dezembro de 1924 da Sociedade Rural Brasileira (SRB), um fórum influente dos fazendeiros, sugeria que os muitos anos de subsídios para a imigração teriam sido melhor aproveitados se o dinheiro tivesse sido aplicado em melhorias de saúde pública:

Não ha hoje assumpto mais importante para a lavoura que a valorisação das populações ruraes pelo saneamento. O trabalhador são vale por dois ou mais trabalhadores doentes. A fazenda saneada equivale a duas fazendas. A colonia inspeccionada e zelada medicamente é uma colonia que se fixa, que se valorisa e que se multiplica

A SRB estava disposta a abandonar a imigração em favor de melhorias na infraestrutura de saúde no campo, elogiando o seu próprio Departamento de Saneamento Rural e o trabalho de Mario Pernambuco, porém sem mencionar a campanha anti-ancilóstomo em andamento da IHB. ${ }^{43} \mathrm{Um}$ tema a ser aprofundado seria o dos vínculos entre a IHB o movimento sanitarista e eugenista, pois o trabalho da IHB aparece no momento em que acontece a transformação do Jeca Tatu de Monteiro Lobato, e foi usado rapidamente por Pena e Kehl em seus textos. No mínimo, o levantamento que a IHB comandou em 1917 e 1918 criou a base científica e material que sustentou as interligações entre o pensamento eugênico e o movimento sanitarista. Possivelmente,

43 "A valorização do homem. Em vez da immigração: hygiene e assistência. Revista da Sociedade Rural Brasileira, 54, 1924, p. 375. 
evidências mais precisas podem ser encontradas no arquivo de Kehl na Casa de Oswaldo Cruz. ${ }^{44}$

O que explica a escolha de determinados locais para os esforços de erradicação do ancilóstomo e estabelecimento de postos de saúde municipais? Os funcionários da IHB eram sensiveis às implicações das suas escolhas de locais para ação filantrópica de saúde pública. As evidências apresentadas sugerem que os locais de filantropia em São Paulo eram negociados entre os funcionários da IHB e as elites do café. A IHB trabalhou na sua primeira área por propaganda, e cafeicultores influentes persuadiram a IHB a atuar em diversos outros locais. O trabalho da IHB em municipios cafeeiros resultou provavelmente menos de um desejo de presença filantrópica em áreas economicamente importantes e mais de uma negociação com o governo (negociação que os funcionários da IHB descreveram à época como questões logísticas). A RF no Brasil "teve que negociar, não apenas impor". ${ }^{45}$

Finalmente, por que foi feito tão pouco para melhorar as condições que levavam ao "solo poluído" e à ancilostomose? Era bem sabido, à época, que as medidas de erradicação do ancilóstomo sem a construção de latrinas levava à reinfecção. Cientistas como Darling e Smillie, como foi argumentado anteriormente, tiveram contato direto com áreas de colonos que necessitavam de melhorias. Os funcionários da IHB deixaram muita responsabilidade para a SSESP; a campanha de erradicação do ancilóstomo também dependia enormemente de brasileiros treinados pela IHB para operações cotidianas. Talvez a IHB não tenha compreendido o contexto político de seus colegas brasileiros, ou a IHB não dispunha de meios para forçar a SSESP a construir as latrinas. Também é possivel que os funcionários da IHB não tenham dado uma prioridade muito alta para a construção das latrinas, preferindo mover-se rapidamente de

\footnotetext{
${ }^{44}$ SOUZA, Raça, 29.

${ }^{45}$ KOBAYASHI, Eugenia, 330. PALMER, Migrant clinics, p. 682, nota que vários estudos rejeitam a noção de que RF foi uma "imposição imperialista." Tambem ver FARIA, Fundação Rockefeller, 564. 
A Fundação Rockefeller e a campanha de eradicação da ancilostomíase...

município para município, fornecendo infraestrutura médica e laboratorial. ${ }^{46}$

\section{Agradecimentos}

Sou grato aos dois pareceristas anônimos da Historical Geography e a W. E. Jepson por seus comentários valiosos nas versões preliminares desse trabalho, e a John LeGloahec e Thomas Rosenbaum por sua ajuda com o material do Rockefeller Archive Center. Agradeço também a Cláudio DeNipoti pela tradução e a José Augusto Leandro pela revisão do texto original. E, por fim, aos editores da Historical Geography pela permissão da publicação da versão em português na RHR - Revista de História Regional.

\section{A Fundação Rockefeller e a campanha de erradicação da ancilostomiase em São Paulo}

(1917-1926)

\section{Christian Brannstrom}

Resumo: A Diretoria Internacional de Saúde (International Health Board - IHB) da Fundação Rockefeller (FR), no início do século XX, desenvolveu atividades para erradicar o ancilóstomo no Estado de São Paulo, como parte de uma atuação mais ampla na saúde pública no Brasil. O estudo das suas atividades revela interações entre a instituição norte-americana e as elites cafeeiras, que começaram a

${ }^{46}$ Ver HEWA, Soma. "The hookworm epidemic on the plantations of Sri Lanka." Medical History 38, 1994, p. 73-90; HEWA, Colonialism, Tropical Disease and Imperial Medicine: Rockefeller Philanthropy in Sri Lanka. Lanham: University Press of America, 1995. Hewa argumenta que os esforços para erradicação do ancilóstomo no Sri Lanka foram prejudicados pela inabilidade de melhorar as condições sanitárias e construir latrinas para evitar reinfecções. 
adotar o discurso de saneamento rural para aumentar a produtivdade dos trabalhadores rurais. O texto localiza as ações da IHB nas áreas de produção cafeeira paulista e aponta o alinhamento entre o pensamento eugênico e o movimento sanitarista no Brasil. Destaca-se a relação entre os fazendeiros e a IHB, e também a relação entre o trabalho da IHB e as figuras públicas como o escritor Monteiro Lobato e dois protagonistas na integração de eugenia-sanitarismo, Belisário Pena e Renato Kehl. O texto ainda relata a situação dos colonos nas fazendas de café, descritas por funcionários da IHB.

Palavras-chave: Ancilostomíase; Café; Saneamento; Eugenia; São Paulo; Rockefeller.

Abstract: The Rockefeller Foundation's International Health Board (IHB) carried out a hookworm eradication campaign in São Paulo state during the early twentieth century as part of a broader public-health campaign in Brazil. Study of the activities reveals interactions between the coffee elite that came to adopt the rural sanitation discourse to increase the productivity of the rural workforce. The paper locates the activities of the IHB in the areas of coffee production in São Paulo, which created one of the scientific arguments supporting the linkages between eugenic thought and the sanitation movement in Brazil. The relation between coffee farmers and the IHB is emphasized, and also the relation between the IHB and public figures such as the writer Monteiro Lobato, and protagonists in the eugenicssanitation movement, Belisário Pena and Renato Kehl. The text summarized descriptions, authored by IHB employees, of the situation of workers on coffee farms.

Key Words: Hookworm; Coffee; Sanitation; Eugenics; São Paulo; Rockefeller.

Recebido : 11/06/2010

Aprovado :10/09/2010 